\title{
Les médecins dans la mire du fédéral - encore une fois
}

Les opinions exprimées dans cet éditorial sont celles de l'auteur et ne représentent pas nécessairement celles de l'Association médicale canadienne ou ses filiales.

1 est déjà difficile de pratiquer la médecine au Canada. La qualité des soins aux patients semble se détériorer de jour en jour. Les nouvelles ressources se font attendre, ou les ressources actuelles sont supprimées. Les gouvernements provinciaux diabolisent la profession médicale. Nos propres représentants semblent désemparés, comme en témoigne entre autres la situation en Ontario depuis quelques années. Aujourd'hui, le gouvernement fédéral juge à propos de se mêler de multiples aspects de la santé plutôt que de s'atteler à bien gérer ce qui relève de sa compétence. Il s'est d'abord immiscé en douce dans le débat public-privé, et voilà maintenant qu'il s'en prend à la façon dont les médecins, les dentistes et tous les autres petits entrepreneurs gèrent leurs affaires en mettant en péril la constitution en société. Les chefs d'entreprise n'auront plus le droit de fractionner leur revenu ni de reporter le paiement de l'impôt de leur société1.

La situation des médecins et des dentistes est en fait légèrement plus difficile que celle de beaucoup d'autres petits entrepreneurs parce qu'ils ne peuvent pas accroittre leurs revenus pour compenser les dépenses supplémentaires engendrées par les changements proposés; les salaires des médecins sont plafonnés par les provinces. Le gouvernement fédéral affirme qu'il est injuste que tout le monde ne puisse pas se constituer en société, mais la plupart des employés ont accès à des avantages sociaux ou à un régime de retraite. Dans un scénario où les médecins entrepreneurs ne pourraient plus reporter leurs impôts, leur capacité à économiser pour l'avenir serait limitée $^{2}$. Si la rumeur se confirme, le gouvernement fédéral prévoit surimposer les propriétaires d'entreprise - qui prennent tous les risques associés à la conduite de leurs affaires de sorte qu'ils soient plus lourdement taxés que leurs employés. En quoi est-ce juste ou souhaitable? De nombreux dentistes sont prêts à lancer la serviette, à mettre la clé sous la porte et à devenir partenaires dans de grandes entreprises. Les fermetures de cliniques dentaires se multiplieront. La même chose se produira en médecine, où les cliniques indépendantes fonctionnent aujourd'hui au seuil de la rentabilité.

Ne sous-estimez pas les effets pervers de cette législation. C'est une attaque contre les moyens de subsistance de la population et l'économie du Canada. Habituellement, la plupart des petites entreprises passent leurs premières années d'existence à se tailler une place dans la communauté. Les revenus sont alors presque totalement réinvestis dans l'entreprise : embauche de personnel, achat et la location de locaux et d'équipement, paiement des consommables. Au cours de la décennie suivante, l'entreprise se stabilise et, à moins de ralentissements du marché de l'immobilier ou d'un revers personnel ou professionnel, l'argent peut s'accumuler dans la société, et l'entrepreneur peut alors planifier sa retraite ou les études de ses enfants. Au moment de la retraite, le propriétaire des actifs de la société paie ses impôts selon le même barème d'imposition que tous les autres Canadiens, en proportion du salaire qu'il aura tiré de son portefeuille de placements. Il s'agit d'un report d'impôt sur de l'argent investi au Canada jusqu'à la retraite de l'entrepreneur - ce n'est pas de l'évitement fiscal. Or, le gouvernement veut cet argent immédiatement, et il prévoit augmenter potentiellement de $700 \%$ l'impôt sur les dividendes dans la plupart des cas - une ponction fiscale qui menace de faillite nos retraités ${ }^{3}$.

Dites adieu aux innovateurs prêts à prendre des risques. Il est plus sage maintenant de chercher un emploi au gouvernement, qui vient avec un salaire garanti et un régime de retraite (en plus d'autres avantages sociaux, comme le régime de retraite de l'employeur, les vacances, les jours fériés et les congés de maladie payés). Autrefois, la fonction publique versait un salaire moindre pour compenser les prestations versées à la retraite. De nos jours, il est plus payant de travailler dans le secteur public que dans le secteur privé, et les avantages sociaux ne cessent de se bonifier. Un de ces jours, la plupart des gens travailleront directement pour le gouvernement un signe de démocratie « dystopique ».

\section{Edward J. Harvey, MD}

\section{Corédacteur, fournal canadien de chirurgie}

Intérêts concurrents: E.J. Harvey est médecin hygiéniste en chef de Greybox Healthcare (Montréal) et président du Conseil d'administration de NXT-Sens Inc. (Montréal).

DOI: $10.1503 /$ cjs.013717

\section{Références}

1. Cestnick T. Proposed tax changes would shake the small-business world. Globe and Mail 201720 juillet. Disponible : https://beta.theglobeandmail. com/globe-investor/personal-finance/taxes/proposed-tax-changes-will -shake-the-small-business-world/article35754872/?ref=http://www. theglobeandmail.com\& (consulté le 7 sept. 2017).

2. Picard A. Ottawa's new tax measures unfairly target many doctors. Globe and Mail 20171 août. Disponible : https://beta.theglobeandmail .com/opinion/ottawas-new-tax-measures-unfairly-target-many-doctors /article35843365/?ref=http://www.theglobeandmail.com\& (consulté le 7 sept. 2017).

3. Paziuk T. Morneau's proposed $700 \%$ tax hike on retired business owners is unfair. Huffington Post 201714 août. Disponible : www. huffingtonpost.ca/tim-paziuk/bill-morneau-to-increase-tax-on-retired -business-owners-by-700_a_23074945/ (consulté le 7 sept. 2017). 